\title{
Multifunctional Carbon Nanotube Film Composite for Structure Health Monitoring and Damping
}

\author{
X. Li, C. Levy*, A. Agarwal, A. Datye, L. Elaadil, A. K. Keshri and M. Li \\ Department of Mechanical and Materials Engineering, Florida International University, Miami, FL USA
}

\begin{abstract}
The goal of this work is to develop and investigate the properties of a new type of multifunctional composite which is based on multi-walled carbon nanotubes (MWCNT). The composite was prepared from a MWCNT "bucky paper" film which was sandwiched between two adhesive layers. Both two point probe and four point probe methods were used to test its mechanical strain sensing properties. The Young' modulus and shear modulus of MWCNT film composite were acquired by the nanoindentation test and direct shear test. A free vibration test was also performed to investigate its structural damping properties. Our research indicated that this new type of carbon nanotube based composite is potentially capable of functioning as a strain sensor and damping device simultaneously for structural vibration control.
\end{abstract}

Keywords: Multifunctional, carbon nanotube, strain sensor, damping.

\section{INTRODUCTION}

Earthquakes are unpredictable natural disasters that can cause devastating losses and damages, especially to human lives and civil structures. Post-earthquake structural damage identification and safety and reliability evaluation are critical for preventing any further damage. Traditional practice mainly relies on visual inspections, which depend heavily on the inspectors' experience. This method is far from sufficient [1], because visual inspection can only detect local and visible damage and cracks. Small cracks resulting from the earthquake may exist underneath the structural surface and beyond the realm of visual inspections. It would be beneficial and crucial to detect and fix the unseen and potential problem during its very early stages.

New methodologies based on vibration measurement and analysis can offer better solutions to this problem. Structural health monitoring employing structural dynamic characteristics such as natural frequencies, modal shapes and modal damping ratios as index for detection of damage have been proposed and investigated intensively during the last two decades $[2,3]$. It also has been reported that changes in higher modal parameters (usually in the higher frequency range) are more sensitive to small cracks $[4,5]$. The most commonly used sensors for vibration measurement are accelerometers and strain gauges. However, their frequency ranges of relevance are usually rather low (up to $100 \mathrm{~Hz}$ ) [6]. Therefore, a new type of sen sor which can provide higher sensitivity in the high frequency range would be better for early crack detection. Our previous research on multiwalled carbon nanotube (MWCNT) film composite sensor indicated that it is better than the foil strain gage for strain sensing in the higher frequency range [7]. In this paper, we continue our

*Address correspondence to this author at the Department of Mechanical and Materials Engineering, Florida International University, Miami, FL 33199, USA; Tel: +1 (305) 348-3643; Fax: +1 (305) 348-1932;

E-mail: levyez@fiu.edu previous work and verify those results by the four point probe test method.

Structural seismic vibration control is another important topic in earthquake engineering. Vibration control devices and strategies can be classified into three groups: passive, active and hybrid. Passive vibration control methods usually apply viscoelastic polymer patches to the structure surface for absorbing and dissipating the seismic energy. On the other hand, the active or/and hybrid methods generally employ sensors and actuators for controlling the input to the dynamics system to suppress its vibration [8]. In this work, we also investigate the damping properties of the MWCNT film composite. It is found that beside its sensing capability, the MWCNT can provide good structural damping at the same time; i.e., this new MWCNT film composite is capable of integrating the transducer or sensor and the damping patch into one element for structure strain sensing and passive/active vibration control.

\section{BRIEF LITERATURE REVIEW}

Since their discovery in 1991 [9], carbon nanotubes (CNTs) have been intensively investigated. Their extraordinary electrical and mechanical properties make them perfect candidates for many potential applications. It has been reported that CNT mechanical deformation and its electrical resistance change are related to each other $[10,11]$, which implies the possibility of using CNTs as nano-scale strain sensors. A more recent study [12] indicated that macro-scale single-walled carbon nanotube (SWCNT) films can act as strain sensors. We reported that this strain sensing property can also be found in the pure MWCNT films [7]. CNT composite films, which are usually manufactured by mixing a small amount $(0.5 \sim 10 \% \mathrm{wt})$ of MWCNT or SWCNT with some sort of polymer, were investigated by a few research groups. All of these CNT composites were reported to have the promising characteristic of a mechanical strain sensor [13-15]. In all of these tests involving applied strain versus carbon nanotube film resistance change, there is an issue of measurement method, namely, the two point probe method 
[13-15] or the four point probe method [12]. Both methods were used for measurement of the CNT film resistance. It has been reported that the resistance of an individual MWCNT measured by two point probe method and four point probe method are different [11]. This result also questions the reliability of the CNT film composite resistance that was measured by these two methods. No comparison experiments have been carried out to clarify this issue, yet, and, hence, it is one of the goals of the present work.

Polymers are typical structural damping materials. A common and effective way to enhance polymer damping capacity is to add carbon fibers with large aspect ratio. Carbon nanotubes are the smallest carbon fibers with much larger aspect ratio and therefore are expected to have better damping enhancement capability. Simulations indicated that the addition of a small amount $(<10 \% \mathrm{wt})$ of well dispersed CNTs into polymer matrices can boost the damping ratio of the composites dramatically [16]. For example, $5 \%$ wt of MWCNT in epoxy can result in $700 \%$ damping ratio increase [17]. Meanwhile, experiments have shown that composites consisting of large amounts of aggregated, highly compacted and tangled CNTs $(>50 \% \mathrm{wt})$ also exhibited good damping properties. Two cases were reported; the first case was a high density pure MWCNT film prepared by the chemical vapor deposition method. Investigation showed that the existence of such a MWCNT film increased the baseline structure damping ratio by $200 \%$ [18]. The second case was a laminated composite manufactured by sandwiching single-walled carbon nanofiber paper/sheet between epoxy layers [19]. A 200-700\% damping ratio increase was reported at higher frequencies. We now report a third case of a laminated composite that was prepared by MWCNT bucky paper sandwiched between two layers of adhesives having good damping characteristics.

Although both the strain sensing property and the damping enhancement property have been reported for CNT based composites, these investigations were reported in an unrelated manner. Previous investigation of the simultaneous strain sensing and damping property characteristics for CNT based composites have never been carried out because the composites were never considered to be multifunctional materials. In this work we report, for the first time, a multifunctional MWCNT film composite, which is potentially able to serve as strain sensor and damping treatment simultaneously.

\section{EXPERIMENTAL SETUP}

Freestanding MWCNT films ("bulky paper") were purchased from Nano-Lab Inc. (Newton, MA) and used "as is". First, the MWCNT film was cut into sensor strips of different sizes, and then electrodes were deposited by the thermal deposition method on both ends of the film strips. The sensors were bonded to the test specimen and sealed with extra adhesive layers on its top. The process for preparing the MWCNT film sensors is shown schematically in Fig. (1). Detailed description on preparation of the MWCNT film sensor and the sensing test results can be found in [7], which presented a comprehensive investigation of the strain sensing property by the two point probe method. For the purpose of completeness and convenience, the static sensing test results by two point method are summarized and presented in Fig. (2). We concluded that the resistance of the MWCNT film changed almost linearly with the applied strain, and the sensitivity factors were comparable to those of the foil strain gages.

Static tensile sensing test results by two point method are summarized and presented in Fig. (2). During the sensing test, the MWCNT films were connected to a Wheatstone bridge. Therefore, their resistance changes were converted to the Wheatstone bridge output voltage change. The applied strain was measured by the foil strain gage. MWCNT sensor and strain gage were bonded to the center of the tensile specimen but on opposite sides. A total of ten samples (sp1 sp10) were prepared and tested and their performances were compared with that of the foil strain gage. We can see from Fig. (2) that the resistance of the MWCNT film changed almost linearly with the applied strain, and the sensitivity factors (which are the slopes of each fitted lines) were comparable to that of the foil strain gage sensor (the black fitted line).

Four investigations were carried out for analysis of the multifunctionality of the MWCNT film composite. They were: i) two point probe and four point probe comparison test for clarifying and verifying the previous conclusion on strain sensing property; ii) nanoindentation test; iii) direct shear test for evaluating mechanical property; and, iv) free vibration test for analyzing the composite's damping enhancement property. The sample preparation, experimental setup and test procedure will be discussed in detail in this

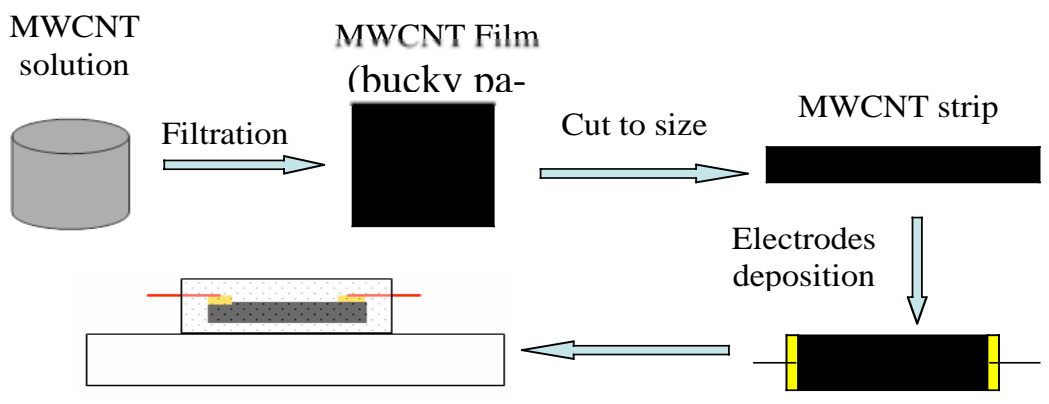

Bonded to structure and sealed by adhesive

Fig. (1). Preparation process of MWCNT strain sensor. 
section. The MWCNT film used in all of these four experiments were exactly the same MWCNT materials as used in [7]. They were purchased and received at the same time and went through the same preparation process.

\section{STRAIN SENSING TEST}

The purpose of this re-analysis of the strain sensing test is to clarify the measurement reliability issue. Three MWCNT film samples were prepared, namely N1, N2 and N3. Each sample was: $50.8 \mathrm{~mm}$ x $12.7 \mathrm{~mm}$ x $0.1 \mathrm{~mm}$. Eight round aluminum electrodes (diameter $=\sim 1.78 \mathrm{~mm}$ ) were deposited on the film surface symmetrically and aligned along the center line by the vacuum thermal deposition method to make solid and stable contact between the film and the probes. Wires were then attached by silver ink to ABCD or 1234 terminals/electrodes (refer to Fig. (3)) to serve as the probes for the four point probe test. In order to compare between the two and four point probe test, two terminals/electrode strips for the two point probe test were also prepared in the same manner. The probe space $\mathrm{S}$ was 12.70 $\mathrm{mm}$. Therefore, $\mathrm{t} / \mathrm{S}$ satisfied the condition for using equation (1) to calculate resistivity and resistance change by the four point probe method [20]:

$$
\begin{aligned}
& \Delta \text { Rsheet }=\Delta \rho / \mathrm{t}=1.9747 * \Delta \mathrm{V} / \mathrm{I} \\
& \Delta \text { Rmeas }=2 \Delta \text { Rcontact }+\Delta \text { Rsample }
\end{aligned}
$$

where in equation (1), the measurement is the four point probe method; $\triangle$ Rsheet is MWCNT film sheet resistance change that is going to be calculated and is considered to be the real value of the MWCNT film resistance change; $\Delta \rho$ is the resistivity change measured; and $\Delta \mathrm{V} / \mathrm{I}$ is the voltage out-

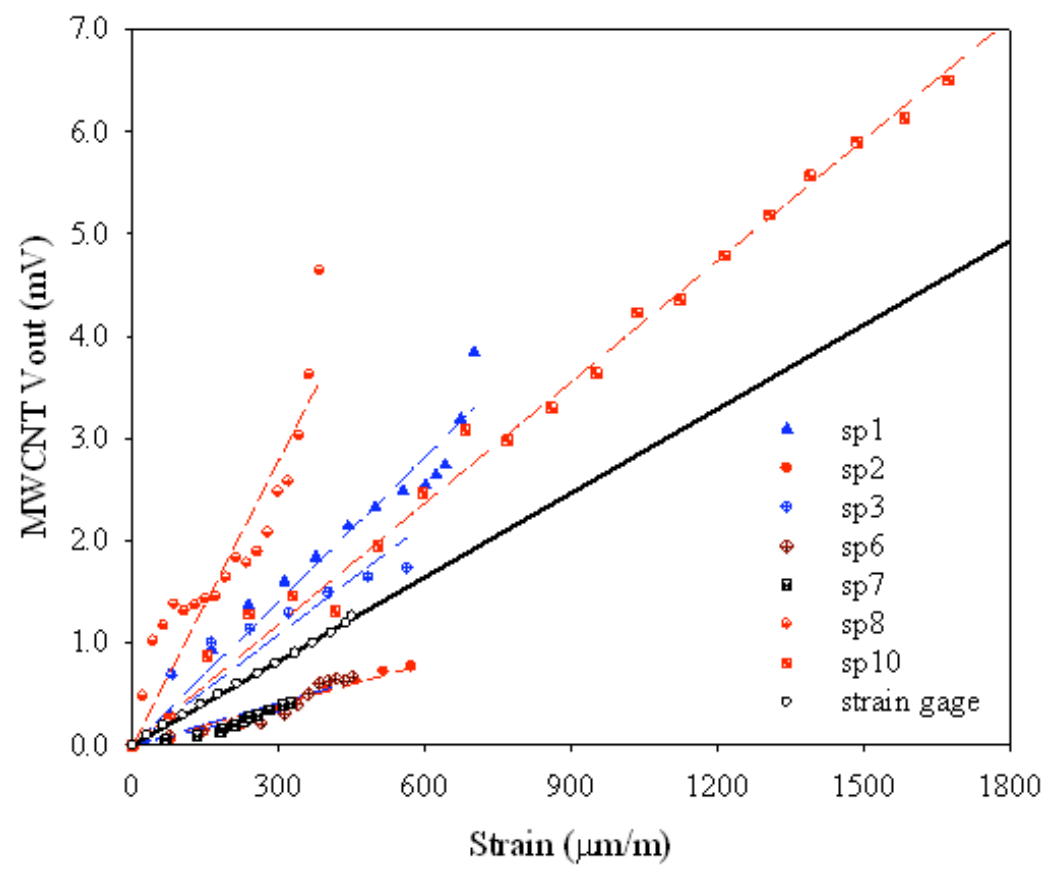

Fig. (2). Previous two point test results: black line is the performance of foil strain gage; all others are test results of different MWCNT film sensors. The MWCNT film sensors showed linearity and sensitivity comparable to that of the foil strain gage.

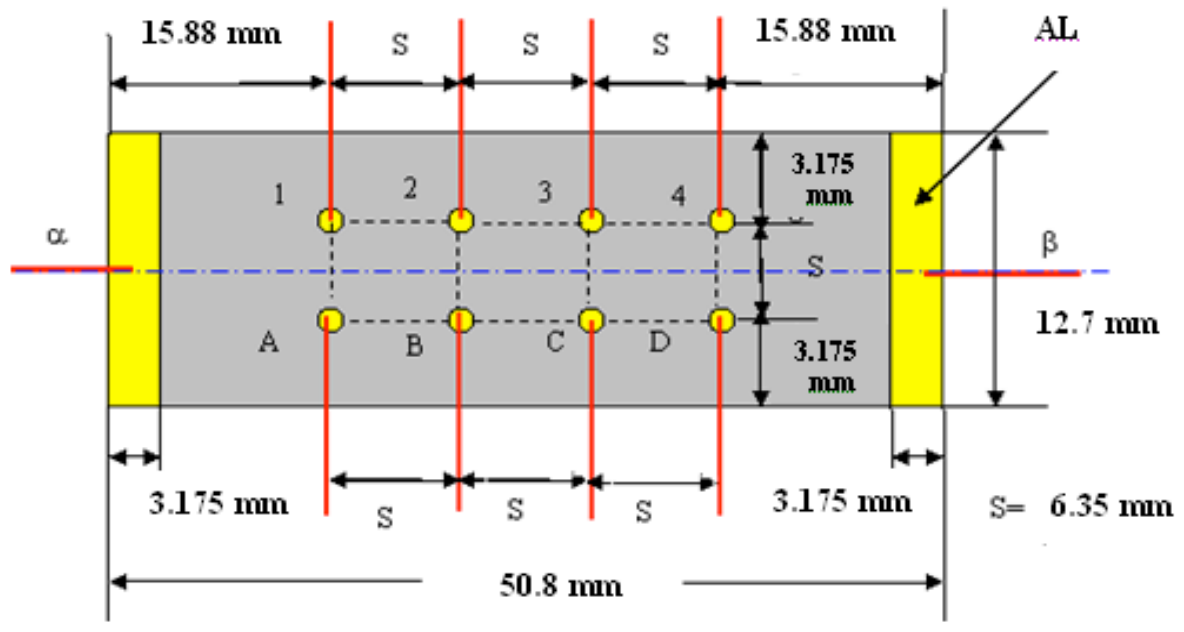

Fig. (3). Configuration of MWCNT specimen for the two point and the four point probe resistance test. 
put reading from the voltmeter. In equation (2), the measurement is for the two point probe method; $\Delta \mathrm{Rmeas}$ is the measured total resistance change, which includes both contact resistance change and the film resistance change itself. This value was calculated from the voltmeter output reading. $\Delta$ Rcontact is the contact resistance change and $\Delta$ Rsample is the MWCNT film intrinsic resistance change, respectively, both unknown values. We will, however, take the $\Delta$ Rsheet from equation (1) as the real value for calculating $\Delta$ Rsample and input the calculated $\Delta$ Rsample into equation (2); the contact resistance $\Delta$ Rcontact can then be calculated. Equation (1) and (2) were used for both strain sensing test and zero load resistance measurement.

The strain sensing tensile test was performed on the same MTS machine and followed exactly the same procedure as described in [7]. Tensile tests were run twice for each sample. The first measurement used the two point probe method with Wheatstone bridge and the second measurement used the four point probe method with direct voltage readings.

\section{MECHANICAL PROPERTY TEST}

The Young modulus is an important parameter of the MWCNT composite film. Information about its mechanical properties is beneficial in the design of the multifunctional components. The traditional tensile test can not be easily applied to small dimensional thin film samples for acquiring the Young modulus. The nanoindentation test and the direct shear test were employed to obtain the Young's modulus for pure MWCNT film and the MWCNT film composite, respectively. The nanoindentation test was carried out on a Hysitron TI 900 Triboindenter. A peak load of $70 \mu \mathrm{N}$ was employed during the test, and each indentation experiment consisted of three steps: loading for 10 seconds, holding the indenter at peak load value for 4 seconds, and then unloading completely in 10 seconds. The measurement sequence consisted of 16 indents.

The direct shear test sample (Fig. (4)) was sandwiched between two aluminum bars. The MWCNT film composite under test was $25.4 \mathrm{~mm}$ x $25.4 \mathrm{~mm}$ x $0.30 \mathrm{~mm}\left(1^{\prime \prime} \mathrm{x} 1^{\prime \prime} \mathrm{x}\right.$ $\left.0.012^{\prime \prime}\right)$. The direct shear test procedure followed the same tensile test methodology employed in [7].

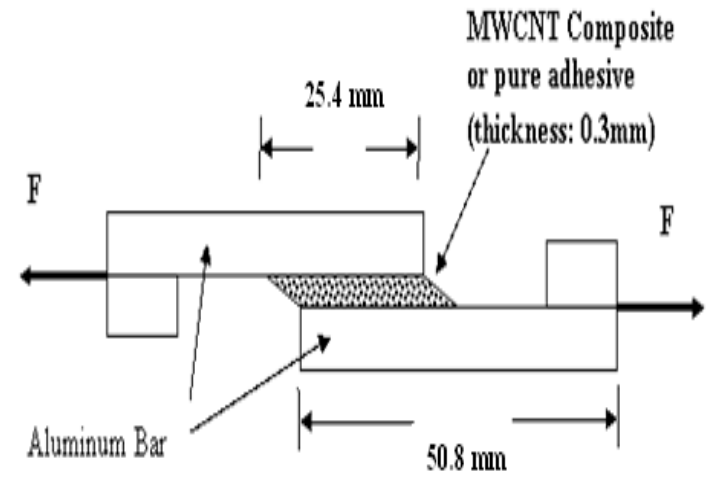

Fig. (4). Specimen for direct shear test: MWCNT film was sandwiched between two aluminum plates.

\section{DAMPING PROPERTY TEST}

A simple aluminum beam $\quad(50.8 \mathrm{~mm} \quad \mathrm{x} \quad 6.99 \mathrm{~mm}$ $\mathrm{x} 2^{\prime \prime}$ x $0.275^{\prime \prime}$ x $0.008^{\prime \prime}$ ) was employed as a base beam for the MWCNT damping property test. Due to the small dimensions of the test samples, free vibration displacement measurement was adopted for the damping test. Two test specimens were prepared: one was a cantilever beam coated with pure adhesive layer and the other was the same cantilever beam yet coated with MWCNT film composite. The composite consisted of one layer of MWCNT film sandwiched between two layers of adhesive (ethyl cyanoacrylate: $70 \%$, Polymethyl methacrylate: $30 \%$ ). Coatings for both specimens were $0.30 \mathrm{~mm}\left(0.012^{\prime \prime}\right)$. The cantilever beam was given the same, small, initial displacement and then released for free vibration. Free end displacements were measured by laser vibrometer (Polytec OFV 2500 controller and OFV 350 sensor head), and a two channel digital oscilloscope (Tektronics TDC 2024B) was used to display and store the vibration signal.

\section{RESULTS AND DISCUSSION}

Fig. (5) shows an example of the strain sensing results from sample N1 by the two point and the four point probe method. Sensitivity factors were calculated by equation

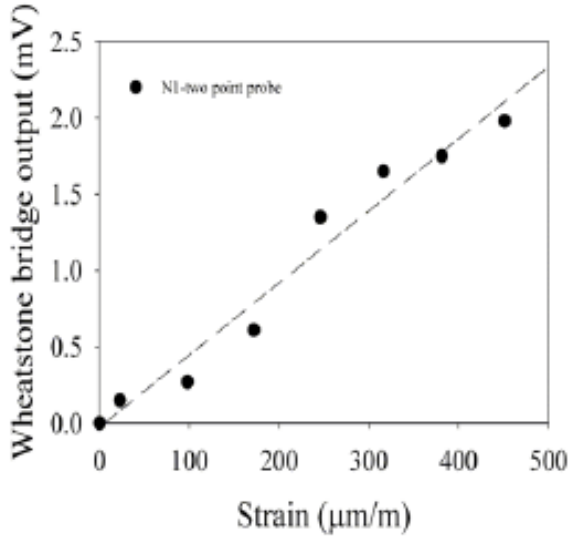

(a)

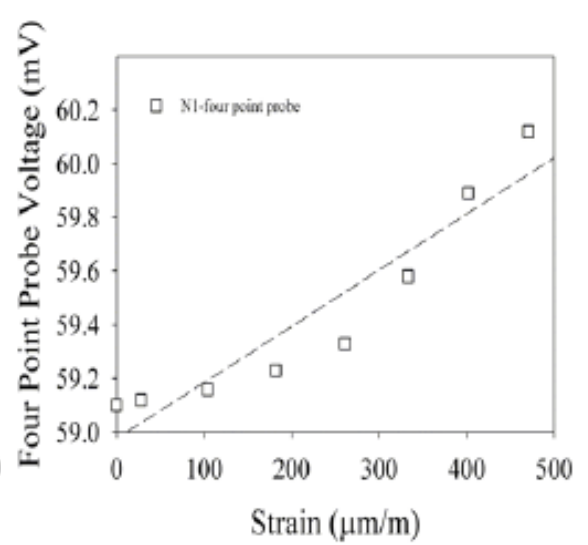

(b)

Fig. (5). Strain sensing test by (a) the two point probe and (b) the four point probe method. 
Table 1. Comparison between the Two Probe and Four Probe Test Results

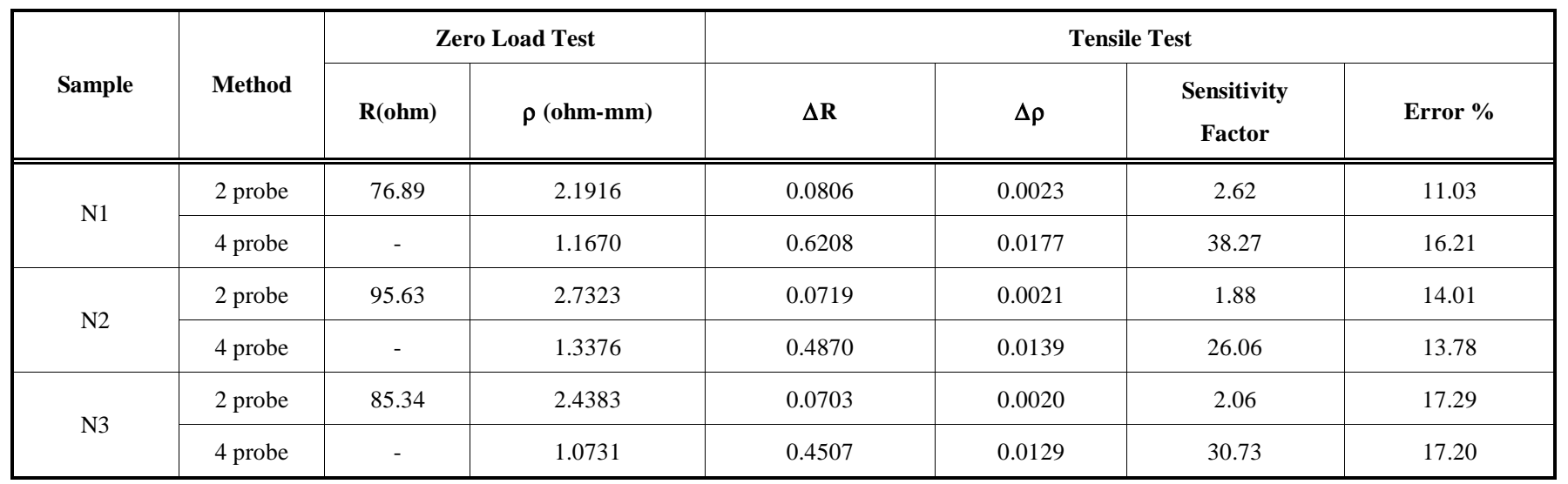

$S F=\frac{\Delta R}{R \varepsilon}$

where $\Delta R$ is the MWCNT film resistance change, $R$ is the original resistance and $\varepsilon$ is the applied strain. Measured and calculated resistance change and resistivity change can also be calculated by equations (1) and (2), respectively.

Data are summarized in Table 1. It can be seen from Fig. (5) that the test results from the four point probe method and the two point probe method shared some similarities. Results by the four point probe method confirmed the conclusions drawn from the two point probe method, i.e., the MWCNT film resistance/resistivity changes with applied strain, but the four point probe method indicates a higher sensitivity factor. The values in the four point probe group were typically about 15 times those of the two point probe group (Table (1)). Also, it can be seen that the four probe method did not show definite improvement in signal linearity (Fig. (5); actually, the measured signal linearity values are close to each other (see global error in Table 1). The linearity result was consistent with another investigator's work [12] who also employed the four point probe method to measure the resistance change of a SWCNT film. Since the four point probe method did not include the contact resistance change and showed much higher sensitivity factors, we would propose to use this method instead of the two point probe method.

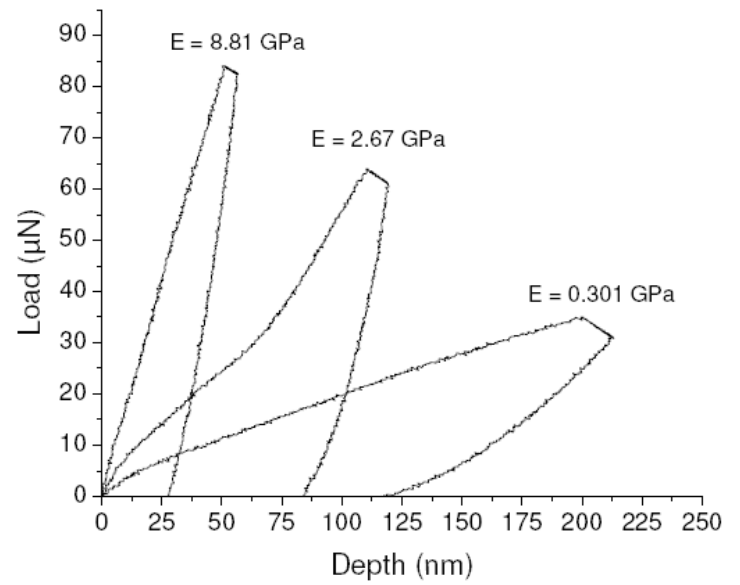

Fig. (6). Nanoindentation test for the MWCNT film.
Using the nanoindentation method, the typical MWCNT film's Young's modulus was found to be in the range of 0.1 $\sim 9 \mathrm{GPa}$ (Fig. (6)). This large variation was due to the porous (relative density 50\%) microstructure of the MWCNT film [7]. The Young's modulus of the MWCNT composite and the pure adhesive material were calculated from the direct shear test (Fig. (7)) and both were found to be around 7.04 $\mathrm{MPa}$. This value was comparable with another group's results [18]. The result indicated that insertion of the MWCNT film into the adhesive did not change the elastic modulus of the composite. The Young's modulus of the MWCNT film ranged from $0.1 \sim 9 \mathrm{GPa}$ by the nanoindentation test, but the mechanical strength of the composite was calculated to be 4.99 $\mathrm{MPa}$ for the pure adhesive and 3.19 $\mathrm{MPa}$ for the sandwich structure, respectively, based on interfacial shear strength. It can be seen clearly that the shear modulus and Young's modulus of the composite were controlled by the adhesive material, while the mechanical shear strength was affected by the existence of MWCNT film.

The damping test results by the method of free vibration decay are shown in Fig. (8). Damping ratios for the structures were calculated using an equivalent single degree of freedom (SDOF) model, namely [21]:

$$
\zeta=\frac{1}{2 \pi m} \ln \left(\frac{x_{1}}{x_{m+1}}\right)
$$

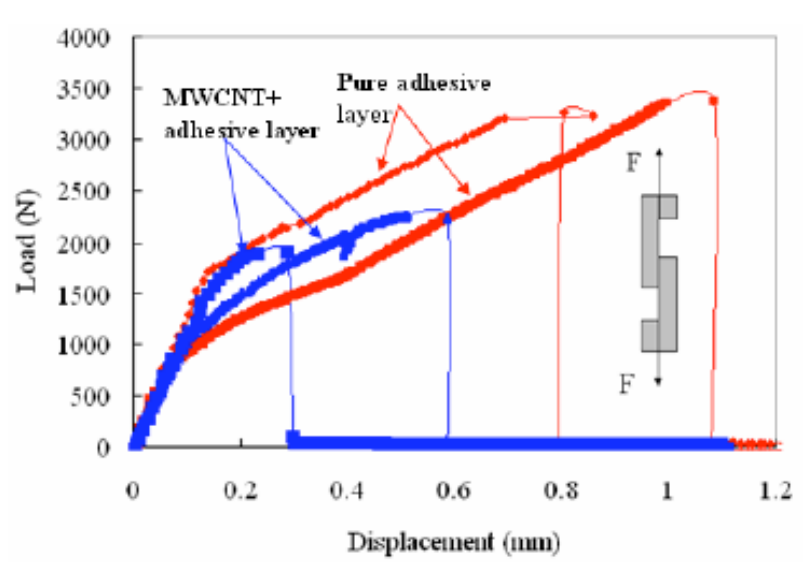

Fig. (7). Direct shear test of the MWCNT composite. 

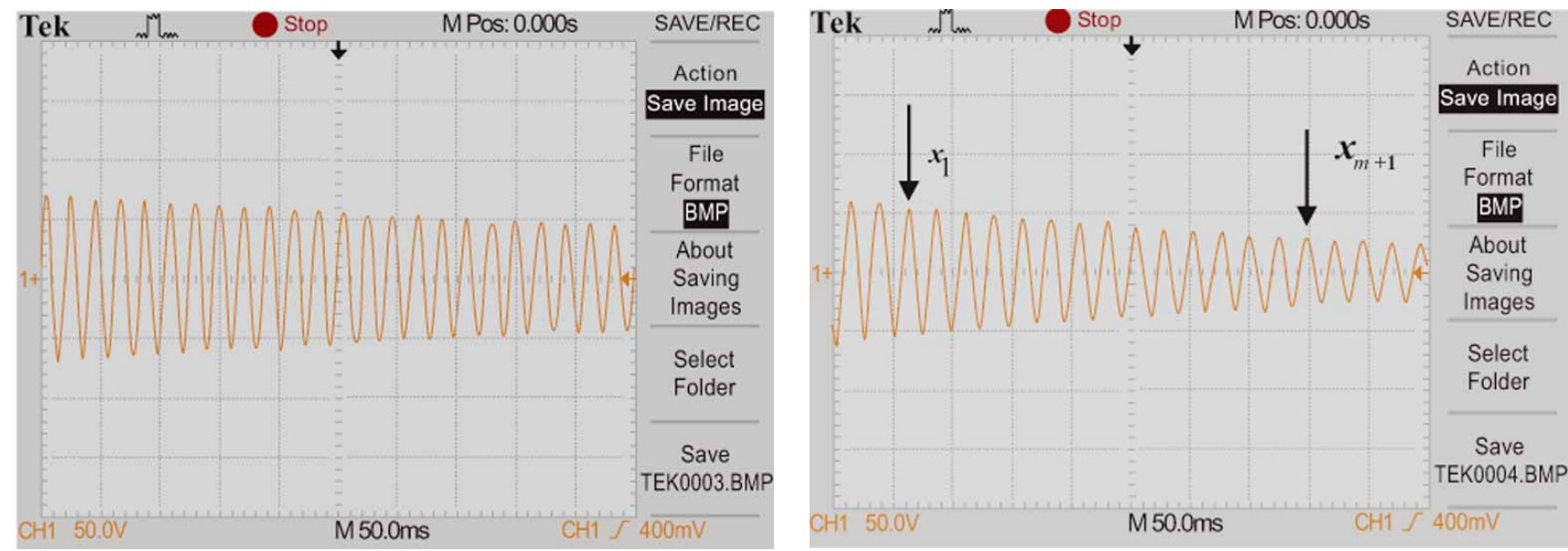

Fig. (8). Free vibration damping test (a): Beam with adhesive only; (b) Beam with MWCNT composite

Table 2. Summary of the Damping Test $\left(f_{1}\right.$ is the System First Natural Frequency, $c$ is the Equivalent Material Viscous Damping Coefficient, $\zeta$ is the System Equivalent Damping Ratio)

\begin{tabular}{|c|c|c|c|c|}
\hline Specimen & Mass (g) & $f_{\mathbf{1}}(\mathbf{H z})$ & $\zeta$ & $\begin{array}{c}\boldsymbol{C} \\
(\boldsymbol{N} \text {-sec } / \boldsymbol{m})\end{array}$ \\
\hline \hline Beam with adhesive & 0.31467 & 48.08 & 0.003129 & 0.000595 \\
\hline $\begin{array}{c}\text { Beam with MWCNT com- } \\
\text { posite }\end{array}$ & 0.35423 & 45.66 & 0.006589 & 0.001339 \\
\hline
\end{tabular}

where $\mathrm{x}_{1}$ is an arbitrary chosen maximum starting point, and $x_{m+1}$ is the $(m+1)^{\text {st }}$ displacement in the sequence thereafter. Here, $m$ is the number of cycles between two measuring points. The test results are summarized in Table 2 . With only $12.57 \%$ extra mass added, the insertion of MWCNT film into the pure adhesive layers increased the structural damping ratio by $110.57 \%$ (from .003129 to .006589). These test results indicated that the MWCNT film composite exhibited a good damping effect.

Using the same SDOF model, the damping characteristic of the MWCNT composite and the system can be calculated. The material viscous damping coefficient, $c$, system stiffness $K$, system mass $M$ and the system natural frequency $\omega$ can be related to the structure's damping ratio as [21]:

$\zeta=\frac{c}{2 \sqrt{K M}}=\frac{c}{2 M \omega}$

The possible reason for the increased damping ratio is that the MWCNT composite had a much higher damping coefficient, $c$, since $K$ and $M$ both increased when extra mass was added to the beam with adhesive coating. This new carbon nanotube film composite material showed a $225 \%$ increase in damping coefficient compared to the pure adhesive materials. Results in this study were compatible with the results of another research group [19].

\section{CONCLUSION}

The four point probe method was carried out to verify previous results obtained by the two point probe method. Results by the four point probe method confirmed the results of the two point probe method, namely, MWCNT film resistance/resistivity changed almost linearly with applied strain. The Young modulus of MWCNT film was measured by nanoindentation testing. Direct shear test results indicated that the insertion of the MWCNT did not improve the Young's modulus of the composite. The mechanical strength of the MWCNT composite was determined by the interface strength between the MWCNT and the adhesive. Free vibration tests indicated that with only $12.57 \%$ extra mass added, the MWCNT film can increase the structural damping ratio by $110.57 \%$. Our results indicate that MWCNT film is potentially capable of concurrently serving as a multifunctional material, i.e., strain sensor and damping treatment, for structural health monitoring and vibration control application.

\section{ACKNOWLEDGEMENTS}

This research is funded by the Army Research Office, Grant No. W911NF-05-1-0391. The authors would like to thank Dr. Kuang-Hsi Wu, and Dr. Ibrahim Nur Tansel for their help in the sample testing. We would also like to thank the reviewers for their comments.

\section{REFERENCES}

[1] S. Soyoz and M. Q. Feng, "Instantaneous damage detection of bridge structures and experimental verification", Structural Control and Health Monitoring, vol. 15(7), pp. 958-973, 2008.

[2] D. D. Montalvao, N. M. M. Maia and A. M. R. Ribeiro, "A review of vibration-based structural health monitoring with special emphasis on composite materials", The Shock and Vibration Digest, vol. 38(4), pp. 295-324, 2006. 
[3] H. H. Kai, W. H. Marvin and J. B. Paul, "Overview of vibrational structural health monitoring with representative case studies", Journal of Bridge Engineering, vol. 11(6), pp. 707-715, 2006.

[4] H. J. Salane and J. W. Baldwin, "Identification of modal properties of bridges", Journal of Structura Engineering ASCE, vol. 116(7), pp. 2008-2021, 1990.

[5] M. A. Mannan and M. H. Richardson, "Detection and location of structural cracks using FRF measurements", The 8th International Modal Analysis Conference, 1990, vol. 1, pp. 652-657.

[6] H. V. D. Auweraer and B. Peeters, "Sensors and systems for structural health monitoring", Journal of Structural Control, vol. 10(2), pp. 117-125, 2003.

[7] X. Li, C. Levy and L. Elaadil, "Multiwalled carbon nanotube film for strain sensing", Nanotechnology, vol. 19, p. 45501, 2008.

[8] M. A. Trindade and A. Benjeddou, "Hybrid active-passive damping treatments using viscoelastic and piezoelectric materials: review and assessment", Journal of Vibration and Control, vol. 8(6), pp. 699-746, 2002.

[9] S. Iijima, "Helical microtubules of graphitic carbon", Nature, vol. 354, pp. 56-58, 1991.

[10] T. W. Tombler, C. Zhou, L. Alexseyev, J. Kong, H. Dai, L. Liu, C. S. Jayanthi, M. Tang and S. Y. Wu, "Reversible electromechanical characteristics of carbon nanotubes under local-probe manipulation", Nature, vol. 405(6788), pp. 769-772, 2000.

[11] S. Dohn, K. Molhave and P. Boggild, "Direct measurement of resistance of multiwalled carbon nanotubes using micro fourPoint", Sensor Letter, vol. 3, pp. 1-4 E.D, 2005.

[12] P. Dharap, Z. Li, S. Nagarajaiah and E. V. Barrera, "Nanotube film based on single-wall carbon nanotubes for strain sensing", Nanotechnology, vol. 15, pp. 379-382, 2004.
[13] G. T. Pham, Y. B. Park, Z. Liang, Z. Chuck and B. Wang, "Processing and modeling of conductive thermoplastic/carbon nanotube films for strain sensing", Composites Part B Engineering, vol. 39(1), pp. 209-216, 2008.

[14] M. Knite, V. Tupureina, A. Fuith, J. Zavickis and V. Teteris, "Polyisoprene-multi-wall carbon nanotube composites for sensing strain”, Materials Science and Engineering C, vol. 27, pp. 1125$1128,2007$.

[15] I. Kang, M. J. Schulz, J. H. Kim, V. Shanov and D. Shi, "A carbon nanotube strain sensor for structural health monitoring", Smart Materials and Structures, vol. 15, pp. 737-748, 2006.

[16] X. Zhou, E. Shin, K. W. Wang and C. E. Bakis, "Interfacial damping characteristics of carbon nanotube-based composites", Composites Science and Technology, vol. 64(15), pp. 2425-2437, 2004.

[17] H. Rajoria and N. Jalili, "Passive vibration damping enhancement using carbon nanotube-epoxy reinforced composites", Composites Science and Technology Journal, vol. 65(14), pp. 2079-2093, 2005.

[18] J. Suhr, N. Koratkar and P. Ajayan, "Damping characterization of carbon nanotube thin films", Proceeding of SPIE, vol. 5386, pp. 153-161, 2004.

[19] J. Gou, S. O'Braint, H. Gu and G. Song, "Damping augmentation of nanocomposites using carbon nanofiber paper", Journal of $\mathrm{Na}$ nomaterials, vol. 32803, pp. 1-7, 2006.

[20] D. K. Schroder, Semiconductor Material and Device Characterization, $3^{\text {rd }}$ ed. Wiley- IEEE Press: New York, NY, 2006.

[21] S. S. Rao. Mechanical Vibrations, $4^{\text {th }}$ ed. Pearson Prentice Hall: New York, NY, 2004. p. 36.

Received: April 04, 2009

Revised: July 04, 2009

Accepted: July 06, 2009

(C) Li et at.; Licensee Bentham Open.

This is an open access article licensed under the terms of the Creative Commons Attribution Non-Commercial License (http://creativecommons.org/licenses/by-nc/3.0/) which permits unrestricted, non-commercial use, distribution and reproduction in any medium, provided the work is properly cited. 